\title{
A walk with Francisco Varela from first- to second- generation networks: In search of the structure, dynamics and metadynamics of an organism-centered immune system
}

\author{
ANTÓNIO COUTINHO \\ Instituto Gulbenkian de Ciência, Oeiras, Portugal
}

\section{A PERSONAL NOTE}

Working with Francisco Varela has always been extremely rewarding: his intelligence, excitement, humor, gentleness, but also solidity in the principles and the arguments, were all there. Perhaps most inspiring was his clarity in identifying the goal, often the essence of the problem at hand, and the path to a solution. And certainly exemplary in a scientist were his openness, his ability to change his opinion, to adapt his frame of mind to new ideas and evidence, if they were appealing and good enough.

I first discovered Francisco's interests in immunology some time in 1977 or so, when Niels K. Jerne, the Director of the Basel Institute for Immunology, gave me a preprint of an article by Nelson Vaz and Francisco on 'Self and non-sense,' a play on words to remind immunologists, often concerned with the conventional 'selfnonself discrimination' question, of their contradictions. This paper considered 'the immune system as a closed network of interactions,' such that "whatever falls outside this domain ... is simply nonsensical" (emphasis mine). While appreciating their provocative views, and joining in their opinion that the current immunological theory was in a great need of shaping up, I did not agree (and I still do not agree today, despite many discussions with Nelson Vaz) that their central claim was right. I continue to think that a 'decision-making behavior' naturally emerges from the immune system's development, structure and operation, allowing for the differential treatment of molecular shapes it identifies either as 'self' or 'nonself.' This is what I learned to designate as 'self-nonself discrimination' and what I have been trying to understand for some 30 years or so. Evolution operates through survivors, and therefore, I thought, invertebrate 'immune systems' should already have such an ability (as they do), upon which the makings of the vertebrate immune system must have been built. This extraordinary 'tumor of lymphocytes' that the vertebrate immune system represents however complex, however rich in unique molecular shapes (V-regions), and however connected these may be in a functional network - must continue to have a survival/ reproductive advantage, namely, to exclude harmful pathogens from the organism while tolerating whatever is necessary for its survival, while making sure that the body itself is not severely harmed by its activity. Hence, its very survival value rests precisely on that ability for 'self-nonself discrimination.'

At the time, I had great expectations that the 'immune network' idea that Jerne had just developed would precisely be the pathway for understanding that central question. I already knew that single antibodies or cell clones have no way of telling the 'selfness' (or lack of it) of any molecule they bind to, and thus I expected that 'self-nonself discrimination' could 
only be a 'distributed property' of the system that emerged from its organization and from its ontogenic history inside an individual body with a unique 'antigenic composition.' A V-region network could provide the supraclonal organization that seemed necessary for such a behavior. Hence, I could not accept that Vaz and Varela would now come and use network ideas to claim that there was no such thing as a 'self-nonself discrimination.' After all, I had started in immunology working with bacterial mitogens that represent, for vertebrate lymphocytes, the 'memory' of the evolutionary past of a non-specific 'selfnonself discrimination,' upon which the 'specific and adaptive' immune system was built.

Life is an arrow in time, and many a general view of biology has lacked this understanding. In other words, different organisms produce different immune systems such that, throughout their development, each 'learns' in which 'self' they were formed, and thus gain the ability to 'discriminate' it from all others. The mechanisms that evolution accumulated to do precisely that were then unknown, and they remain the central question today, nearly 30 years into this tremendous wave of progress in the identification of the immune system's components. I was little inclined, therefore, to engage in solipsistic network views and was far more inclined to 'put the network back into the body,' something I thought was missing in the original theory. This amounted, before anything else, to studying animals prior to their immunization, in other words, to analyze the 'autonomous' activity in the system. This could only be the result of endogenous interactions within the system and with the rest of the body. I thought that Maturana, Varela, and Vaz were making the same mistake that Jerne had already made: they were closing the immune system in itself as an ivory tower, isolating it from the organism, as if the antibody combining sites could tell the difference between binding to another $\mathrm{V}$-region in the immune network, or to transferrin, for example, that they saw 'outside' the network.
A few years later, I was invited by Nelson Vaz to come to Brazil for a meeting of the SBPC (Sociedade Brasileira para o Progresso da Ciência), then very much a stronghold of opponents to the autocratic regime and a rare forum for free exchange of ideas in the country. I never found out why I had been invited - perhaps because I am a Portuguese, or perhaps because Nelson was interested in exposing the audience to some of the contradictions in current theory, as I always enjoyed doing. At this meeting in Brazil, I met Francisco and Humberto Maturana, and I will owe this to my good friend Nelson for the rest of my life. While not hesitating to express his ideas and to underscore his arguments, Francisco struck me immediately as being truly interested in the others' knowledge, opinions and position. He did not give 'lectures' aimed only at convincing the others of his own views, and discussions with him were always bi-directional.

Some time later, Francisco moved to Paris, and we were then in the best of conditions to continue the discussions we had begun in Brazil. We also became close friends. Sometimes we worked in Pasteur, sometimes in Jussieu, but our preferred 'office' was undoubtedly the Café des Écoles, particularly on Saturday mornings, where life and science were never separated.

Thus, regardless of the results of our work, much of the fun was in meeting and talking about all sorts of exciting things in science, biology and life in general. Francisco introduced me to several other interesting people, and our seminars at the Pasteur Institute soon became an exciting reunion of interesting, if odd, people discussing 'interdisciplinarity,' complexity, cognition, network theory, auto-organization and autopoiesis. Among the first who joined us was John Stewart, a geneticist of thousand and one qualities with whom I continue to have the privilege of collaborating, now in Oeiras. (As I discovered it later, John was encouraged to come to Pasteur after 'discovering' immunology through Nelson Vaz in a meeting at beautiful Cerisy where they both were.) As the work progressed, several of my colleagues at the laboratory in Pasteur and elsewhere in Paris became 
increasingly involved, and soon we had several papers describing this work. Francisco and John both made tremendous contributions by adding a wider view of biology to our education as immunologists. In complete disorder, Dan Holmberg, Carlos Martinez-A., Frederic Jacquemart (who never agreed with anything), Tomaz MotaSantos, Anne Sundblad, Alf Grandien, Miguel-Angel Marcos, José Faro, Evelyne Malenchère, Luiz Andrade, Inger Lundqvist, Claudia Peña-Rossi, Denis Portnoi, Francois Huetz, Michel Kazatchkine, Mário Arala-Chaves, Alberto Nobrega, Pablo Pereira, António Bandeira, Rita Vasconcellos, Jorge Carneiro, Yves Modigliani and Constantin Fesel were, perhaps, among those who profited the most. The ground work had already been laid, I must say, at least as I see it today, for Nelson Vaz had previously spent some time at the Pasteur Institute and had greatly helped my colleagues and me precisely 'to put the immune network back in the body,' as we wrote in a paper on 'organismcentered immunology' that we published in 1984.

I also had the privilege of introducing Francisco (and Nelson) to Niels Jerne and watch the development of a great empathy that was established between them. For the years to come, all the way to his death in 1994, Jerne, bored with the detailed descriptions of molecules and cells, would often turn to me and suggest that we should, instead, talk 'Brazilian immunology,' which was exciting, creative, profound, organism-centered, network immunology. Just two years before he died, in one of his last letters to me (recently published by Ivan Lefkovits in a collection of Jerne's writings), Jerne suggested that we should "think more practically of writing, with Francisco and Irun (Cohen), an article (perhaps PNAS) revealing some absurdities of clonal selection." And he finishes the letter writing, "I should be glad to talk this over with you and Francisco, perhaps best after the Budapest meeting?" We never wrote this article, but we had it all clear in our minds.

Unsatisfied with the then existing immune network theory, we attempted to improve it. Even the 'second generation networks' that Francisco and I introduced in the field, however, brought us into what seemed to be a dead-lock, a feeling also shared by John Stewart. We could not imagine an immune network isolated from the rest of the body, predicting therefore, that immune activities would have an impact on other body systems and functions. In our (overly?) simple experimental approaches, however, we could not demonstrate physiological properties outside the system itself and of its own activities. (Incidentally, some such effects were later described by Philippe Druet and colleagues in hypertension, by the same 'Irun' of whom Jerne was speaking, in the regeneration of nerve lesions, and, recently, in the contribution of lymphocytes to wound-healing.) It seems to me that this apparent impasse promoted the progressive disengagement of Francisco from Immunology, together with his increasing excitement with the up-coming techniques for the global analysis of brain activities. It is indeed extremely exciting when a technical window is opened in such a way that an idea you 'always' had can finally be put through experimental scrutiny. I understood this so well that I was tempted to enter the new field of brain imaging myself.

Obviously, Francisco asked his question and got the answer his views had predicted. It was very rewarding to see that he received instantaneous applause and recognition for this contribution that was to be his last. I had the pleasure of having him in Lisbon for a couple of closed symposia that he was kind enough to put together along with Jean-Pierre Changeux, and I could witness his brilliance and enthusiasm - already very affected in his physical condition - in presenting his data and ideas.

Anybody who knew Francisco could certainly go on forever talking about him, his character and qualities, and about his fundamental scientific contributions as well. I think, however, that those who did not know him well will never understand his charm, and the following will not help either: Francisco simply owned the 'head of the snake.' In science, I believe that the most important aspect of his personality 
was that he did theory and practice, bringing them together in a most productive manner. I have great respect for theoreticians and for empiricists as well, but the 'complete scientist' is both, and Francisco was one of these few.

FROM THEORY TO THE BENCH AND BACK TO MODEL BUILDING: NATURALLY ACTIVATED CELLS AND NATURAL ANTIBODIES

\section{Structure, dynamics and metadynamics}

When Francisco and I started working on theory and modeling of 'immune networks,' we quickly realized that all the models thus far had essentially concentrated on interactions among free antibody molecules, giving little or no attention to the biology of the cells that produce such antibodies, and also express the corresponding Variable(V)-regions on their surface. In a first simplified approximation, we essentially postulated that interactions of B cells with the network were determined by the connectivity of the respective $\mathrm{V}$ regions to pre-existing soluble antibodies in serum and had distinct functional consequences according to a bell-shaped dose-response curve for ligand binding to surface antibody receptors that had previously been empirically determined. Both very low and very high levels of interaction would lead to cell death, while intermediate levels would result, for increasing values of ligation, in (1) cell survival in the resting state, (2) cell activation to antibody secretion with minimal proliferation, and (3) cell proliferation with little or no antibody secretion. (For specialists, we also assumed that these responses were likely to be $\mathrm{T}$ cell-dependent, but decided to leave this complication for later, as discussed below).

Our models distinguished, therefore, among lymphocytes according to their activation state, and started to include distinct Prol and Mat functions to describe the dynamics of clonal cell numbers versus the concentration of the respective clonal products. We also took the view that cell bound V-regions, while constituting functional 'targets' for the network dynamics, would have per se a negligible contribution to the network. Thus, such Vregions are produced at infinitesimal concentrations (a total of some 100,000 molecules only), and, being cell bound, they seemed to have no way to significantly participate in the global network structure and dynamics. It follows that resting lymphocytes would contribute little or nothing to the network structure, which was built by serum antibodies and the cells that produce them. We thus introduced a major distinction between activated, antibody-secreting B cells and the 100fold more numerous resting lymphocytes. In addition, we included in the models the notion of $B$ cell dynamics, the rates of production of new $\mathrm{V}$-regions in the bone marrow, their turn-over rates in the resting lymphocyte compartment, and the rates of their activation and differentiation to antibody-secreting plasma cells. In some way, by dealing with the 'flesh and bones' of the network (the biology of the cells that integrate it), we were, for the first time, attempting to produce realistic models. This was well accepted by the theoretical community, and soon thereafter other groups started working on similar types of models. In short, we limited the participation of resting $B$ cell receptors in the network structure, but enriched the network dynamics with the biology of cell activation and maturation. By including cellular activation, but distinguishing clonal expansion from maturation to antibody secretion, we underscored the variations in the concentrations of circulating antibodies that were derived from the activation of specific B cells to secrete antibodies at rates that are at least 3 or 4 orders of magnitude higher than prior to their activation.

John Stewart soon added his efforts to ours, producing models of minimal networks with very interesting dynamics. Furthermore, John and Francisco went on to produce new models for the recruitment of newly-formed B cells into the network structure. These had the value of demonstrating the possibility that the actual repertoires of V-regions in serum antibodies 
recursively select, from the wealth of novel shapes continuously emerging in the bone marrow, the available repertoires of resting lymphocytes from which novel possibilities for the network could eventually be recruited. As soon as we introduced B cell dynamics (production from precursors and turn-over of mature cells), however, we had to consider the probability that newlyformed B cells produced a V-region (idiotype) that was unique and thus different from all pre-existing ones. We predicted that the probability of producing a repeat was low to very low (a prediction that was later confirmed experimentally), such that realistic mathematical models of the network had a real problem. As in all networks, we had to consider the immune network structure (V-regions, their ligands and respective interactions) and the timedependent dynamics of its variables (variations in time of the concentrations of antibodies and respective clones). In addition, however, we also had to consider the system's ability to continuously produce new variables all together. We decided to introduce the term 'meta-dynamics' to emphasize and describe such a continuous production of new variables. John and Francisco wrote papers about it, I personally thought this was most elegant and descriptive and even added it to my slides, only to receive a rather cold comment from Niels Jerne, after reading one of our papers. "You know," he said, "to add "meta' as a prefix to scientific matters has had a bad reputation ever since Aristotle wrote his book on Metaphysics."

As this work was launched, the "bench side' in the laboratory was focusing on natural antibodies, the circulating immunoglobulins that every normal vertebrate produces, seemingly in a spontaneous manner, as they are found normal in animals that are secluded from all antigenic contacts with the environment. We thought that such antibodies represent the internal activity of the immune system and embody the respective network. Interestingly, we quickly found that these antibodies bind to 'self' and are often 'multireactive,' thus re-enforcing my view that the network could not be isolated from the rest of the body, and that other 'self' proteins (perhaps all) participate in its structure. Thus, the same autoantibodies were also integral parts of the network, connected to a large number of other antibodies in the same individual. The immune network was, finally, 'put back into the body,' that is, shown to include antibody V-regions and other 'self' molecules. There was only one difference between these two classes of molecules, namely, their respective dynamic properties: the rate of production of any given antibody can change over 1,000,000 fold in one week, while the concentrations of most other body molecules are kept within relatively narrow physiological ranges.

The simulation of the models did suggest an interesting aspect of the system's dynamics, namely that, while total immunoglobulins levels in serum are kept constant, the concentrations of specific natural antibodies fluctuate in time, around a 'strange' attractor with characteristic 'chaotic' dynamics. Having set up the tools to follow individual V-region idiotypes in normal sera, we looked at this prediction. Indeed, natural antibody concentrations did fluctuate in a time-dependent manner, mostly over 1 order of magnitude or so. Furthermore, the intravenous injection of sub-microgram amounts of natural antibodies in saline was a sufficient 'perturbation' to result in specific 'compensations' in the concentrations of complementary antibodies and in marked alterations in the dynamics of the respective time-dependent fluctuations. We concluded that a functional network did operate among natural autoreactive antibodies. Moreover, the comparison of healthy donors with individuals suffering from autoimmune diseases for the dynamics of natural antibody fluctuations revealed differences that excited us tremendously, Francisco in particular (as I was quite lost with Fourier transformations and spectral types). Thus, in pathological autoimmune situations, it looked as though the system had lost its characteristic 'chaotic' behavior, rich in evolutive possibilities, to be fixed in 'noisy' or cyclic dynamics. For a time, this seemed 
to provide the distinctive characteristic between health and disease that many of us had been searching for long. However, the small number of points in the time series we could produce, due to the limitations in bleeding and testing men or mice hundreds of times, prevented us from reaching firm conclusions. We decided to postpone these experiments until the appropriate technology was available.

\section{Second Generation Immune Networks}

It was not difficult to convince Francisco of my reservations on the original network ideas and on the current models of the immune network, for some of these had been instigated by Francisco himself. Quickly, therefore, we realized the profound differences between the models we were now using and the original network models. The major difference was, of course, that essentially all initial models were trying to explain and describe specific, clonal immune responses to external antigens. In contrast, we were attempting to describe the internal activity in the immune system as an autonomous behavior of the immune network, well anchored in the rest of the body. At the center of these differences were the respective objectives: we wanted to understand the selection of 'pre-immune' repertoires and the establishment of tolerance to body components (the old 'self-nonself discrimination'), while others had been interested in explaining clonal immune responses and specific memory.

Having made the step of excluding resting B cells from significantly participating in the network structure, we realized that clonal immune responses were well explained by Burnet's clonal selection theory and, as such, required no network at all (they could readily be induced in culture, with a random small fraction of the whole system, even with single clones). Furthermore, such immune responses to 'nonself' were known to be initiated by resting lymphocytes. Obviously, we dared to go all the way, postulating that specific responses to 'nonself' antigens had little or nothing to do with the immune network, and suggesting that network immunology should rather concentrate on studying distributed properties emerging from a network organization, for which clonal immunology had provided no solution. As, for example, natural tolerance and physiological autoreactivity, as well as the selection of 'pre-immune' V-region repertoires.

Meanwhile, at the bench side, we had continued to work on naturally activated $\mathrm{T}$ and B lymphocytes and had demonstrated that natural serum antibodies and activated $\mathrm{B}$ cells do influence the $\mathrm{V}$-region repertoires of other activated cells (both B and T). In contrast, resting $B$ and $T$ cells had no such effects. Together, these theoretical and empirical observations led us to propose the 'second generation immune networks.'

The central idea here was to restrict a network organization to naturally activated, autoreactive $\mathrm{B}$ and $\mathrm{T}$ cells, while considering that resting, mature lymphocytes are functionally disconnected from the network. With hind-sight, this seems quite obvious for immunophysiologists. Thus, resting lymphocytes are obviously devoid of effector functions and mitotically inactive, such that we can positively state that they are not productively stimulated by the network. We then designated by central immune system (CIS) the compartment of activated, autoreactive and V-region connected lymphocytes - that represented some 10$15 \%$ of the total lymphocyte numbers - and severed from the network the remaining $85-90 \%$ of all lymphocytes in the lymphoid organs. These would only represent potential network targets for eventual recruitment through activation, in case the network space would evolve to include them. Moreover, we proposed, these resting lymphocytes were in ideal conditions to respond to external antigens, as they were disconnected from regulatory influences of the network, such that conventional antigens can provide the specific stimulation as predicted in Burnet's clonal selection theory. This view also brought in a bonus derived from the original theoretical concerns with $\mathrm{V}$-region concentrations in 
the organism. Thus, it seemed possible that the disconnected clones and respective antibody V-regions, once specifically activated and amplified a 1,000,000 fold or so by antigen, would now reach the range of concentrations that matters for the network structure and dynamics. In other words, antigenic experiences leading to the production of new antibodies entering the network would impinge in the network organization, allowing for the formation of a 'systemic memory.' Conversely, expanded clones would in turn find in the network structure their internal ligands that would allow for their long-term maintenance, even in the absence of nominal antigen. This was perhaps the first attempt to use 'systemic memory' to explain the characteristics of recall responses by clones that were initially disconnected from the immune network, thus including into realistic network concepts the phenomenon of long-term immunological memory.

Finally, the proposal allowed for a simple mechanism in the selection of pre-immune repertoires by having the network of circulating immunoglobulins contributing to the repertoire of internal ligands that selects the emerging, newly formed B (and T) cells. Actually, our postulate that lymphocyte survival in the resting state was determined by 'connectivity' levels of the respective $\mathrm{V}$-regions to the pre-existing network of natural antibodies (between thresholds for survival and for activation), did rescue the inclusion of resting lymphocytes in the network - the purist's point of view. In a way, however, this notion was too advanced for the time, for only recently it became clear that lymphocyte survival in the resting state does require continuous/repeated interactions with internal ligands, as we had postulated long ago.

Our proposal had, however, the major heuristic value of bringing two views of the immune system into compatibility that had formerly seemed irreducible to each other: the clonal selection and the network theories. Within this framework, both theories could be accepted, but each applied to distinct parts of the system, as they had indeed been derived to explain different questions. The specificity and amplification of immune responses to external antigens, for the former, versus the selection of "preimmune' repertoires for the latter, and, as we had it, natural lymphocyte activation, self-tolerance and the biology of autoreactive cells. In addition, our view explicited the dynamics and some of the mechanisms operating in the productive interface between these two compartments, leaving thus to Caesar what belonged to him.

\section{Epilogue with hind-sight}

More than 20 years later, I continue to consider that this particular idea fits most of the observations that immunological theory has to explain, and I have seen nothing that would decrease its explanatory value. Furthermore, the theory provides an understanding for some of the phenomenology that has remained unexplained by other views, as for example, 'clonal dominance' in both $\mathrm{B}$ and $\mathrm{T}$ cell responses to external antigens. Moreover, in my view, the notion incorporates, better than current alternatives, the 'evo-devo' of the immune system, notably the fact that immune repertoires can not but start as a dense, autoreactive network, due to the genetic and developmental imposition of structural $\mathrm{V}$-region properties that make them extremely connected and 'multireactive.'

Finally, the recent revival of 'dominant tolerance,' based on the selection of autoreactive lymphocytes for regulating anti-self immunity, can only be accommodated in wider theories of this type, and make no sense within the framework of either the "clonal selection theory' or the 'first generation immune network theory.' It is now clear that natural self-tolerance cannot be established in immune systems that operate entirely on a 'one clone by one clone' basis, nor can it operate in 'closed immune networks' that fail to learn the antigenic composition of the body where they develop.

Our original proposal, however, had two major forces against it: first, the 
irreducibility of the defenders of either the network or the clonal selection theories. Jerne himself, while agreeing with much of the argument, did not like our proposal at all, as he thought it removed the beauty of a single integrated system. This was an unfair critique, as I argued, because the proposal addressed Jerne's concern with 'what precedes clonal selection,' and actually used the network to select all preimmune repertoires and to decide which clones integrate a functional network and which are ascribed to the clonal responses to antigens. In addition, our theory postulated a central role for Jerne's lifetime preoccupation - the natural antibodies and, in its most precise interpretation, lets the network determine the survival (and activation) of all lymphocytes, including those that remain at rest.

Defenders of clonal selection, on the other hand, did not like it either, as the theory still included a network with the fundamental role of repertoire selection ('pre-immune' and, eventually, 'memory'). Worse for these, however, was our suggestion that autoreactive lymphocytes, with affinities for the internal environment that fell between activation and deletion thresholds, would be kept integrating the network, providing the molecular and cellular basis for the interface between the immune system and the rest of the body, that is, for natural self-tolerance. With the rise of the simplistic notions of 'tolerance by clonal deletion,' it was obvious that our proposal could not survive for long. Ironically, it has now become widely accepted, even often defended by the very champions of 'deletion', that self-tolerance is 'dominant' and mediated by autoreactive lymphocytes.

An optimist like Francisco would perhaps believe that our 'second generation network' ideas will come back to light, eventually through the extraordinary clinical effects of the network (circulating immunoglobulins) on pathological autoimmunity, possibly through the generation and/or maintenance of those regulatory cells. At any rate, it is high time to use the framework of 'second-generation networks' in attempting to integrate the recent views on 'regulatory $\mathrm{T}$ cells' and 'dominant tolerance' with the 'evo-devo' of repertoires and the 20-years oldobservations on the reciprocal and recursive selection amongst 'naturally-activated $\mathrm{T}$ and B cells.'

At least two fundamental elements were missing, however, even in 'second generation network' models. The first was to account for Nelson Vaz' concerns with mucosal immunity. He kept reminding us that most lymphocytes in the body are at the mucosal surfaces, that mucosae extend by over $200 \mathrm{~m}^{2}$, and that most of the physiological antigenic contacts of the organism happen precisely through this route. Furthermore, in many cases, the results of antigenic exposure vary widely if they take place at the mucosae or systemically. Our theories, on the other hand, were limited to 'conventional lymphoid organ immunology.' Given all the observations that Nelson Vaz and his colleagues have produced on the properties of 'perturbations' introduced by oral/nasal exposure to foreign antigens, this is certainly something that should be dealt with, within the framework of second generation networks.

The second missing step in our original formulations was, as seen above, the inclusion of specific T cells in the network structure and dynamics. These are lymphocytes with specific receptors that secrete no antibodies but have the ability to stimulate or suppress, specifically or unspecifically, the secretion of antibodies by other cells. Luckily, this deficit has been corrected: Jorge Carneiro joined the group and decided, along with John Stewart, to do just that. Francisco and I had little to do with this elegant piece of work, but it clearly represented a development of the previous concerns. Moreover, regardless of the impact of this work on the network theory, the fact is that Jorge soon became a recognized theoretical immunologist, and much of what he continues to produce, now in Oeiras, has to do with T cells and with tolerance. And he continues to share and pass on to his students the basic idea that theoretical models must be realistic and, therefore, are better done somewhere 
between the bench and the computer. This, I believe, was perhaps the most relevant contribution of the 'Paris School' that Francisco uniquely helped found.

As it must have become clear in the above discussion, our work together moved increasingly to the 'bench side,' mostly due to my incompetence in real modeling. On the other hand, Francisco continued to develop these ideas and approaches, now with several other collaborators, maintaining a strong influence in the field. Eventually, he decided that brain biology (which he had never left either in the lab or in his mind, even when deeply involved in immunology) was more likely to provide the system to test his general, fundamental idea. Interestingly, his demonstration that the network selects what it pays attention to, which, in turn, reverberates through good parts of the whole structure and adds to the memory of past experiences in selecting what we pay attention next, is not principally different from the 'second generation immune networks' that he offered to immunologists.

\section{UNIVERSAL SCIENCE}

By the late 1980's the possibility appeared to seriously consider the installation of a new institute in Portugal, and Francisco shared this idea with great enthusiasm. We were a group of a half-dozen or so scientists in our mid-40's who were truly determined to leave our permanent positions, to come together and give our best to launch a "new deal' in biology. Again, however, we were all too early in our arguments for the need of hypothesis-driven, organism-centered research in modern biology, which would be concerned with 'global properties' rather than with components and would promote transdisciplinarity between areas of biology with similar limitations, as we felt they existed in neurosciences, immunology and genetics. Now, nearly 15 years later, Francisco would have liked to see the current concerns of the establishment with 'systems biology,' with 'global analyses' of gene expression, with 'gene networks,' even with multivariate analyses of gene expression data. On the other hand, he would have been the first to remind us of the fact that understanding will not crystallize spontaneously out of a pile of data, that linear causality must be used with great caution, if at all, and that doing science, first of all, involves great fun and intellectual excitement.

At the time, however, our proposal of an Institute for Universal Science did not convince the decision-makers, perhaps because the acronym would have been 'Institute for US,' as we used to joke. Years later, we received a serious proposition that, had it been made earlier on, would have brought Francisco (and some others) to Portugal. It was too late, however, for the original project. We had all become 10 years older, probably more sour than before with the arrogance and intellectual limitations of the gene cloners, and had given up most of our strength to start all over again. Moreover, Francisco had found the environment and the set-up to do the research he wanted in Paris. As a consequence, I lost the pleasure of seeing him regularly, but I hope that he would have liked the Gulbenkian Institute as it is today. And I gained the excitement to meet him, in Paris, in Lisbon, or in conferences elsewhere, always enjoying his brilliance, his creativity, his generosity that precluded all proselytism, and his serious concern for science.

Clearly, Francisco's goal was to understand life and to go through it with elegance, excitement and entirety. I was very lucky to share this short walk with him: both my science and my life would have been far poorer had I not met Francisco Varela.

\section{SELECTED REFERENCES}

This paper is obviously a very personal recollection, taken directly from my memories, as I did not go back to confirm all the dates and the proper order of events. The bibliographical references listed below are those that, in my opinion, best summarize Francisco Varela's contribution to Immunology. I have only included 
publications written or co-authored by Francisco and thus had to leave out many others with his influence.

CALENBUHR V, BERSINI H, STEWART J, VARELA FJ (1995) Natural tolerance in a simple immune network. J Theor Biol 177: 199-213

COUTINHO A, ANDERSSON A, SUNDBLAD A, LUNDKVIST I, HOLMBERG D, ARALA-CHAVES M, STEWART J, VARELA FJ (1990) The dynamics of immune networks. In: OSTERHAUS A and UYTDEHAAG F (eds) Idiotypic Networks in Biology and Medicine. Amsterdam: Excerpta Medica. pp: 5963

DETOURS V, BERSINI H, STEWART J, VARELA FJ (1994) Development of an idiotypic network in shape space. J Theor Biol 170: 401-14

DIETRICH G, VARELA FJ, HUREZ V, BOUANANI M, KAZATCHKINE MD (1993) Selection of the expressed $B$ cell repertoire by infusion of normal immunoglobulin $\mathrm{G}$ in a patient with autoimmune thyroiditis. Eur J Immunol 23: 2945-50

HUETZ F, JACQUEMART F, PENA ROSSI C, VARELA FJ, COUTINHO A (1988) Autoimmunity: the moving boundaries between physiology and pathology. J Autoimmunity 1: 507-518

LUNDKVIST I, COUTINHO A, VARELA FJ, HOLMBERG D (1989) Evidence for a functional idiotypic network among natural antibodies in normal mice. Proc Natl Acad Sci USA 86: 5074-8

STEWART J, VARELA FJ, COUTINHO A (1989) The relationship between connectivity and tolerance as revealed by computer simulation of the immune network: some lessons for an understanding of autoimmunity. J Autoimmunity 2: 15-23

STEWART J, VARELA FJ (1989) Exploring the meaning of connectivity in the immune network. Immunol Rev 110: $37-61$
STEWART J, VARELA FJ (1990) Dynamics of a class of immune networks. II. Oscillatory activity of cellular and humoral components. J Theor Biol 144: 103-115

STEWART J, VARELA FJ (1991) Morphogenesis in shapespace. Elementary meta-dynamics in a model of the immune network. J Theor Biol 153: 477-98

VARELA FJ, SANCHEZ-LEIGHTON V, COUTINHO A (1989) Adaptive strategies gleaned from immune networks: Viability theory and comparison with classifier Systems. In: GOODWIN B, SAUNDERS PT (eds) Theoretical Biology: Epigenetic and Evolutinary Order (A Waddington Memorial Conference). Edinburgh: Edinburgh University Press. pp: $112-123$

VARELA FJ, COUTINHO A (1990) Immune networks: getting on to the real thing. Res Immunol 140: 837 846

VARELA FJ, ANDERSSON A, DIETRICH G, SUNDBLAD A, HOLMBERG D,

KAZATCHKINE M, COUTINHO A (1991) Population dynamics of natural antibodies in normal and autoimmune individuals. Proc Natl Acad Sci U SA 88(13): 5917-21

VARELA FJ, COUTINHO A (1991) Second generation immune networks. Immunol Today 12: 159-66

VARELA FJ, COUTINHO A (1991) Immunknowledge: the immune system as a learning process of somatic individuation. In: BROCKMAN JE (ed) The Reality Club. New York: Prentice Hall Press. pp: 237-256

VARELA FJ, COUTINHO A, STEWART J (1993) What is the immune network for? In: STEIN WD, VARELA FJ (eds) Thinking about Biology. Redwood City, CA: Addison-Wesley. SFI studies in the Sciences of Complexity, Lect Note Vol III: 215-230

VARELA FJ, COUTINHO A, DUPIRE B, VAZ NM (1988) Cognitive networks: immune, neural and otherwise. In: PERELSON AS (ed) Theoretical Immunology. Redwood City, CA: Addison-Wesley. pp: 359-374

VAZ NM, VARELA FJ (1978) Self and non-sense: an organism-centered approach to immunology. Med Hypotheses 4: 231-67 